\title{
Effects of oil absorption of mineral on masterbatch flowability and processability of filled-polymer \\ Zhou Xueyong ${ }^{1, a^{*}}$, She Chongmei ${ }^{2, b}$, Liu Huifen ${ }^{2, c}$
}

\section{College of Food Science and Bioengineering, Tianjin Agricultural University, Tianjin, China 300384}

2. College of Agronomy and Resources Environment, Tianjin Agricultural University, Tianjin, China 300384

ae-mail address: zhouxueyongts@163.com; ${ }^{b}$ e-mail address: dzxydlxscm@163.com;

ce-mail address: liuhuifen@eyou.com. *corresponding author: Zhou Xueyong.

\section{Keywords: Mineral; Oil absorption; Masterbatch; Flowability; Processability; Filled-polymer}

\begin{abstract}
Effects of oil absorption of mineral and masterbatch flowability on the processability of filled-polymer were studied. Two kinds of cheap minerals (bentonite and calcium phosphate) were chosen as the experimental materials. The results showed that the oil absorption of bentonite was higher than that calcium phosphate, but its processability and filling amount in polymer was lower that of calcium phosphate. This research concluded that the higher the oil absorption, the lower the masterbatch flowability, accordingly, the film-formability decreased. The mineral with lower oil absorption had higher filling amount.
\end{abstract}

\section{Introduction}

With the development of petrochemical industry, plastic products such as polyethylene, polypropylene and polystyrene are widely used. It is very known that the petroleum resource is non-renewable, therefore, the reduction of the consumption of the synthetic polymers is an important measurement for sustainable development ${ }^{[1]}$. However, restrictions on the use of synthetic polymers will lead to an adverse effect on the world economics, the appropriate method for solving this problem is to search for the alternative materials. Currently, the mineral-filled polymers are widely used in cars, cables, furnishings and plastic bags, the usage amount of filled-polymers increases $5 \%-8 \%$ each year ${ }^{[2-3]}$. The polymers filled by mineral powder have several advantages: (1) the lower cost. As the price of mineral powder is 10 to 15 times lower than that of polymer, the manufacturing cost of the filled-polymer is lower than that of pure polymer; (2) the better performance. The filling of mineral in polymer can improve some performances, such as the hardness, elasticity modulus, dimensional stability and thermostability; (3) more friendly to the environment. The plastic products have caused serious environment pollution due to their difficult degradation. The filling of mineral in polymers can improve their photo-degradability ${ }^{[4]}$.

The previous researches showed that the properties of filled-polymers are associated to the types of materials ${ }^{[5]}$. However, what characteristics of minerals can influence the processing performance of polymers has received little attention. In this study, we choose two kinds cheap minerals: bentonite and calcium phosphate. The oil absorption of mineral and masterbatch flowability is investigated, the relationship between the oil absorption of mineral and film formability is analyzed. The results will give important reference to the studies of filled-polymers.

\section{Materials and Methods}

Experimental Materials. Calcium phosphate, 300 mesh, Yunnan Chemical Research Institute. Bentonite, 300 mesh, Heinan Xinyang Yucai Bentonite Limited Corporation. Titanate coupling agent, SG-Ti 131, Nanjing Shuguang Chemical Factory. White Oil (No. 10), Wuhan City Petrochemical 
Company. Paraffin, Fushun City Yuanyang Wax Limited Corporation, Liaoning Province. Polyethylene wax (molecular weight 2000), Zhejiang Ninghai Chemical Limited Corporation. Linear polyethylene (DFDA-7042), Qilu Petrochemical Company. Low-density polyethylene(1F7B), Beijing Yanshan Petrochemical Corporation.

Experimental Equipment. Machinery for mixture, SRL-Z200/500A, Zhang Jia-gang Yili Machinery Corporation, Jiangsu province, China. Twin-screw compounding extruder, SHJ-68A, Mechanical Research Institute of Chemical Industry Ministry, China. Blow-molding machinery, SJZM-40/28-450, Screw diameter of $40 \mathrm{~mm}$, length diameter ratio is 28:1, Santou Machinical Factory, China. Machine for tensile testing, XLDW-03, Institute of Science and Education Instrument, Jilin University, China. Melting Index Tester, XRZ-400-1, Mechanical Factory of Jilin University, China.

Determination of Oil Absorption of Mineral. The oil absorption of bentonite and calcium phosphate was determined according to the method described by Zhou et al. ${ }^{[6]}$. The di-butyl phthalate was used as the testing reagent.

Activation of Mineral Powder. The mineral powder was put into the activation equipment, then it was heated to $100^{\circ} \mathrm{C}$ and dried for $15 \mathrm{~min}$. The adding ratio of the titanate coupling agent was $1.5 \%-2.0 \%$ of the mineral powder. The activation time was controlled $15 \mathrm{~min}^{[7]}$.

The Preparation of Masterbatch. The preparation formulation for masterbatch is shown in Table1.

Table 1 Preparation formulation of masterbatch

\begin{tabular}{cc}
\hline Materials & Percentage $(\%)$ \\
\hline Mineral powder & $75.0-82.0$ \\
Paraffin & $1.5-5.0$ \\
Calcium stearate & $1.0-5.0$ \\
Polyethylene wax & $1.5-5.0$ \\
Low-density polyethylene & $10.0-20.0$ \\
\hline
\end{tabular}

The twin-screw compounding extruder was heated to the required temperature. The mixed materials containing modified filler, carrier resins, dispersants and lubricants were added into the machine from a hopper. The masterbatch was prepared during this process ${ }^{[8-9]}$.

Blowing Film Technology. The mixed carrier was comprised of LDPE/LLDPE=3:1, the filling amount of mineral powder in film was $15 \%$ 20\% (w/w). The ratio of blowing: inflation ratio was 3 , the traction speed was $28 \mathrm{~m} / \mathrm{min}$, and the screw speed was $40 \mathrm{r} / \mathrm{min}$. The temperature control conditions: the first district was $160 \sim 170^{\circ} \mathrm{C}$, the second district was $170 \sim 175^{\circ} \mathrm{C}$, the third district was $175 \sim 180^{\circ} \mathrm{C}$, and the fourth district was $180 \sim 190^{\circ} \mathrm{C}$. The thickness of film was $0.02 \sim 0.025 \mathrm{~mm}$.

The Mechanical Testing of the Films. The stretchability testing was carried out to determine the tensible strength and breaking elongation.

\section{Results and Analysis}

The Oil Adsorption of Mineral Powder. The oil adsorption of bentonite and calcium phosphate was showed in table 1 . The results showed that the oil adsorption of bentanite was higher than that of calcium phosphate.

Table 2 The oil adsorption ratio of mineral powder

\begin{tabular}{cc}
\hline Minerals & Oil adsorption $(\%, \mathrm{w} / \mathrm{w})$ \\
\hline Bentonite & 2.5 \\
Calcium phosphate & 2.0 \\
\hline
\end{tabular}


The Melt Index of Masterbatch. The melt index reflects the liquidity of masterbatch under the blowing-film conditions. If the flowability is high, the mixing performance of masterbatch with polymer will be better. Table 3 showed that the melt index of calcium phosphate was much higher than that of bentonite. Through the contrast Table 2 and Table 3, the results showed that the oil adsorption of minerals was inversely proportional to the melt index of the masterbatch.

Table 3 Effects of mineral types on melt index

\begin{tabular}{ccc}
\hline Minerals & Mineral content $(\%)$ & Melt index of masterbatch $(\mathrm{g} / \mathrm{min})$ \\
\hline Bentonite & 10 & 2.56 \\
Bentonite & 15 & 1.04 \\
Calcium phosphate & 10 & 19.6 \\
Calcium phosphate & 15 & 10.7 \\
Calcium phosphate & 20 & 8.35 \\
\hline
\end{tabular}

Mechanical Properties of Filled-films. When the filling amount of mineral powder in film was $15 \%$ to $20 \%(\mathrm{w} / \mathrm{w})$, the thickness of filled-films was $25 \mu \mathrm{m}$. The effects of mineral types on the mechanic properties of filled-films were shown in Table 4.

Table 4 Effects of mineral types on the mechanical properties of filled-films

\begin{tabular}{cccccc}
\hline Minerals & $\begin{array}{c}\text { Mineral content } \\
(\%)\end{array}$ & \multicolumn{2}{c}{$\begin{array}{c}\text { Tensible } \\
\text { strength(MPa) }\end{array}$} & \multicolumn{2}{c}{ Breaking elongation (\%) } \\
& & Vertical & Horizontal & Vertical & Horizontal \\
\hline Bentonite & 15 & 20.2 & 21.8 & 170.6 & 659.6 \\
Bentonite & 20 & 21.3 & 20.6 & 158.2 & 421.7 \\
Calcium phosphate & 15 & 13.3 & 9.6 & 307.5 & 680.1 \\
Calcium phosphate & 20 & 15.2 & 11.7 & 258.6 & 479.3 \\
\hline
\end{tabular}

When the filling content was fixed, the tensible strength of film filled by bentonite was higher than that filled by calcium phosphate, however, the breaking elongation of the former was lower than that of the latter. Furthermore, the lower the oil adsorption, the higher the filling content of mineral in polymer.

\section{Discussion}

In theory, the higher the filling amount of mineral filler in plastics, lower costs of the product ${ }^{[10]}$. However, the filling proportion of mineral cannot be too high, otherwise the tensile strength and breaking elongation of the filling polymer will decrease significantly. The filler particles are actually separated in the matrix resin of continuous phase, therefore, the stress of section of filled resin is less than pure resin, even if there are no holes or bubbles between filler particles and matrix resin. Under the action of external force, the matrix resin is easily separated from the filler particle surface. Nielsen ${ }^{[11]}$ derived a tensile yield equation when there is no adhesion between fillers and polymer under the basis of simple tension model. According to the theoretical calculation of the model, the tensile strength will reduce to almost zero when the filler volume is more than $75 \%$. Under such circumstances, filler particles can be contacted directly.

\section{Conclusion}

The oil adsorption of mineral was related to the masterbatch flowability and film-formability. The higher the oil adsorption of minerals, the lower the masterbatch flowability and film-formability. The mineral with lower oil adsorption has higher filling potential. In addition, the bentonite and calcium 
phosphate are cheap raw minerals with extensive sources. The above results will give reference to industrial production of filling polymers.

\section{Acknowledgements}

The research was funded by the National Natural Science Foundation of China (No. 31470573) and (No.31070478).

\section{References}

[1] A. Cranfield Ltd., Mineral-filled polyester sounds better, Reinforced Plastics, 39(1995)4.

[2] Y. J. Liu, Progress on the application of calcium carbonate in plastics, Inorganic Chemicals Industry, 40 (2008)11-13.

[3] C. DeArmitt, K.D. Breese, Filled polypropylene: a cost-performance comparison of common fillers,Plastics Additives and Compounding, 3(2001)28-33.

[4] L. Husarova, M. Machovsky and P. Gerych, Aerobic biodegradation of calcium carbonate filled polyethylene film containing pro-oxidant additives, Polymer Degradation and Stability, 95(2010)1794-1799.

[5] K.H. Rao, K.S.E. Forssberg and W. Forsling, Interfacial interactions and mechanical properties of mineral filled polymer composites: wollastonite in PMMA polymer matrix, Colloids and Surfaces A: Physicochemical and Engineering Aspects, 133(1998)107-117.

[6] X. Liu, X. Zhou, L. Qu, Q. Yao and H. Wang, The direct characterization for the modified filler by oil absorption ratio, Advanced Materials Research, 549 (2012) 625-629.

[7] Z. Y. Zhang, G. C. Qin, and Y. Chi, Study on refining ground calcium carbonate in plastic and vertical roller mill technology", China Non-Metallic Mining Industry Herald, 5(2010)45-47.

[8] P. Rungruang, B. P. Grady and P. Supaphol, Surface-modified calcium carbonate particles by admicellar polymerization to be used as filler for isotactic polypropylene, Colloids and Surfaces A: Physicochemical and Engineering Aspects, 275(2006)114-125.

[9] C. Deshmane, Q. Yuan and R.D.K. Misra, On the fracture characteristics of impact tested high density polyethylene-calcium carbonate nanocomposites, Materials Science and Engineering: A, 452-453 (2007)592-601.

[10]Liu Yingjun, Liu Boyuan. Plastics filling and modification. Beijing: China Light Industry Press, 2000, pp.7-20.

[11] Dong Yanming. Modifocation and processing of filler[J]. Hunan Plastics, 1 (1983) 20-23. 